\title{
Infrastructuring the Imaginary
}

\author{
How Sea-Level Rise Comes to Matter in the San Francisco Bay Area \\ Robert Soden \\ Computer Science \\ University of Colorado Boulder \\ Boulder, Colorado, USA \\ robert.soden@colorado.edu \\ Nate Kauffman \\ Landscape Architecture \& Environmental Planning \\ University of California Berkeley \\ Berkeley, California, USA \\ natekauffman@berkeley.edu
}

\begin{abstract}
Information infrastructures have become integral components of policy debates related to climate change and sustainability. To better understand this relationship, we studied the tools used to forecast and respond to sea-level rise in the San Francisco Bay Area, where active debates on how to best prepare for this issues are underway and will have important consequences for the future of the region. Drawing on 18 months of qualitative research we argue that competing visions of the problem are intimately intertwined with different elements of information infrastructure and beliefs about the role of data in policymaking. Current infrastructure in the region, far from being a neutral actor in these debates, exhibits an infrastructural bias, privileging some approaches over others. We identify some of the tactics that community organizations deploy to subvert the claims of sea-level rise experts and advance their own perspective, which prioritizes considerations of justice over technical expertise.
\end{abstract}

\section{CCS CONCEPTS}

Human computer interaction $(\mathrm{HCI}) \rightarrow \mathrm{HCI}$ theory, concepts and models

\section{KEYWORDS}

Climate Change; Crisis Informatics; Environment; Infrastructure; Civic Technology; Science and Technology Studies

\section{ACM Reference format:}

Robert Soden and Nate Kauffman. 2019. Infrastructuring the Imaginary: How Sea-Level Rise Comes to Matter in the San Francisco Bay Area. In 2019 CHI Conference on Human Factors in Computing Systems Proceedings (CHI 2019), May 4-9, 2019, Glasgow, Scotland, UK. ACM, New York, NY, USA. Paper 286, 11 pages. https://doi.org/10.1145/3290605.3300516

Permission to make digital or hard copies of all or part of this work for personal or classroom use is granted without fee provided that copies are not made or distributed for profit or commercial advantage and that copies bear this notice and the full citation on the first page. Copyrights for components of this work owned by others than ACM must be honored. Abstracting with credit is permitted. To copy otherwise, or republish, to post on servers or to redistribute to lists, requires prior specific permission and/or a fee. Request permissions from Permissions@acm.org.

CHI 2019, May 4-9, 2019, Glasgow, Scotland UK

(c) 2019 Association for Computing Machinery.

ACM ISBN 978-1-4503-5970-2/19/05...\$15.00

https://doi.org/10.1145/3290605.3300516

\section{Introduction}

In 2012 a local artist and technologist released a series of short blog posts describing everyday life and politics of San Francisco in the year 2072, after the occurrence of 200 feet of sea-level rise. The series, entitled "San Francisco Archipelago", includes fictional future news stories discussing rapid population growth of the city, legal battles over tech industry's unwillingness to pay local taxes, unreliable public transportation, and a proposed bond measure to build an expensive floating sports stadium just off the island of Alcatraz. The anchor of the work is a set of realistic maps of San Francisco, much of which is depicted as underwater or as a constellation of small islands-an archipelago-as the result of sealevel rise. Through an intensification of select contemporary political issues and the portrayal of a balkanized landscape upon which these struggles play out, San Francisco Archipelago delivers a compelling portrayal of one possible future of the region. It doing so, it acts as a critique of present-day life and politics in the region and an attendant call for change.

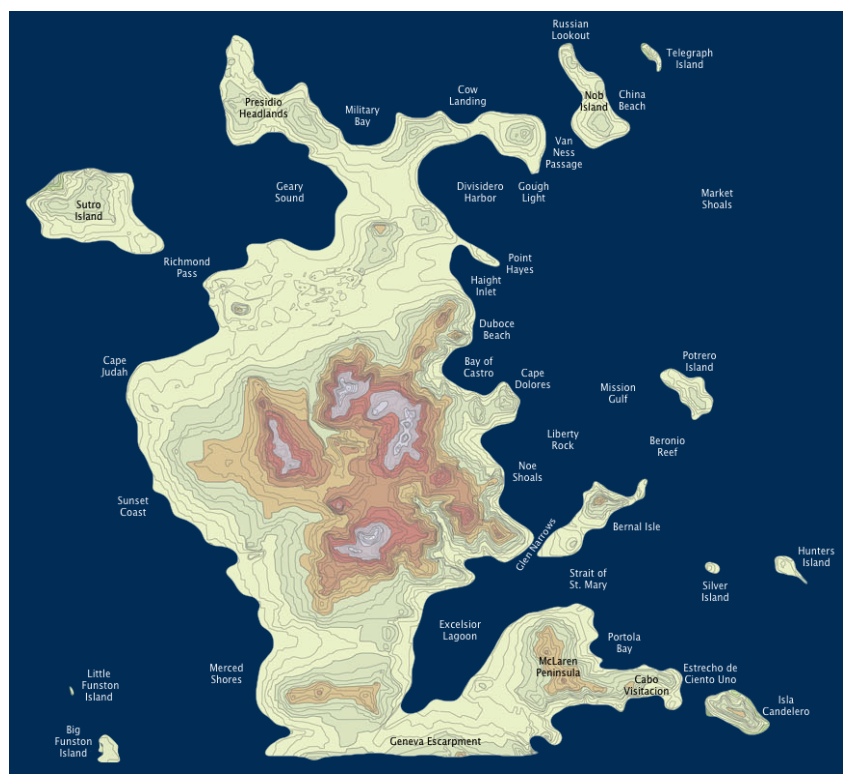

Figure 1: The San Francisco Archipelago [9]

Other depictions of the future of the Bay Area have been less selfconsciously dystopian, though no less political. In 1949 John Reber, in a fit of post-World War II industrial optimism, proposed a 
radical reshaping of the region's ecological and infrastructural landscapes. His plan included damming the major rivers that flow into the Bay, constructing massive causeways that would separate the north and south reaches of the Bay from the Pacific Ocean, the infill of over 80 square kilometers of the bay's shallow marshes and mudflats, and a major expansion of development and industrial and military installments focused on the central Bay. To assess the impacts of "the Reber Plan", the US Army Corps of Engineers constructed an enormous 320 by 400 foot working hydrologic model of 1600 square miles of the San Francisco Bay and surrounding deltas. The model draws 135,000 gallons of water per day through its channels, canals, and rivers, simulating the interplay between hydrology, the physical landscape, and the built environment of the region. It helped show that Reber's ideas were unfeasible, and although the Plan was scrapped by the early 1960's, the Bay Model is still functional and open to tourists and school trips. A small exhibit on geographic information systems (GIS) reminds visitors that engineers and scientists now develop these kinds of models every day on laptop computers with greater ease and precision.

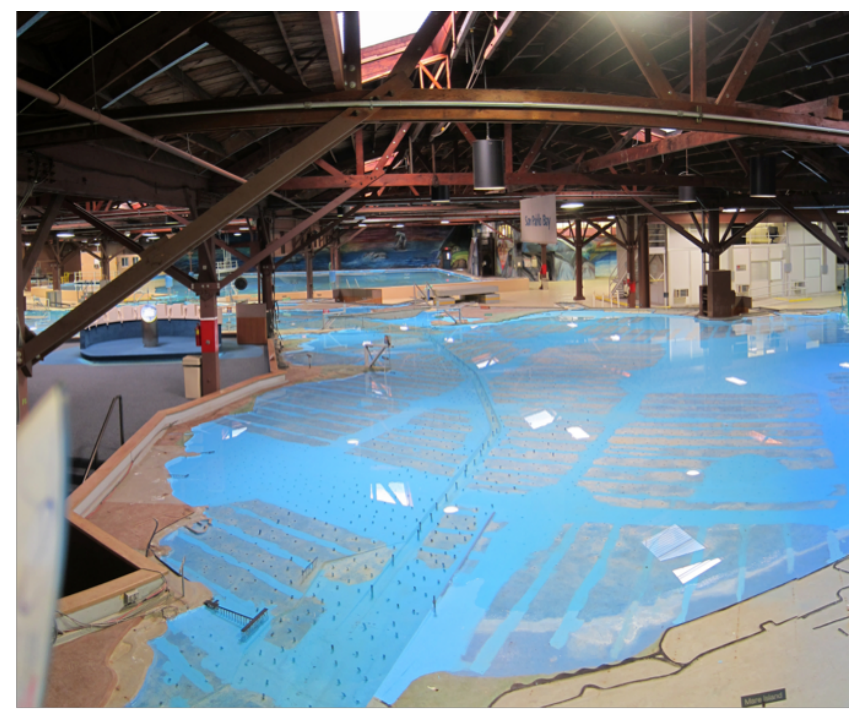

Figure 2: The Bay Model (photo by authors)

Human settlements have long been entangled with the wetlands ringing the shallow estuary that is the San Francisco Bay. Over the past two centuries, this relationship has included the effort to create more land to accommodate increasing population and high demand. In the 100 years leading up the Reber plan, over 400 square miles of land was produced through infill and drainage, reducing the size of the Bay by one third of its total area. Today, as a result of sea-level rise driven by anthropogenic climate change, the Bay is expanding again. There are great uncertainties involved in forecasting the rate at which this could happen, but some models anticipate as much as 24 " before 2050 and 60 " before 2100 , which could put at least 270,000 people at risk of flooding during storm events and threated billions of dollars of property and infrastructure [6]. There are a number of efforts underway involving local and regional government, universities, engineering and architecture firms, and civil society organizations to plan for and develop responses to protect low-lying areas against rising waters. Such efforts, and the technologies that inform them, are bound up with the region's complex history and ongoing struggles over it's future.

The maps, models, software, and databases that experts use to understand and represent the environment are formidable salvos in struggles over what human geographers have called "the environmental imaginary". In post-structural terms, environmental imaginaries are discourses - specific configurations of knowledge, ideology, and practice - that shape the ways in which human societies interact with the environment [42]. In a similar fashion, science and technology studies (STS) scholars have developed the concept of "socio-technical imaginaries" to describe the contentious processes by which technology and technical practice continually reshape the landscape of possible action and delimit potential futures [28]. The concept of imaginary is thus a powerful tool for describing the interconnections between socio-technical systems, values and politics, and the environment. In this paper we examine the relationship between competing imaginaries of sealevel rise and the information infrastructures that experts, policymakers, and the public depend upon to respond to this challenge in the San Francisco Bay Area.

Our research identified three distinct imaginaries that are competing to influence sea-level rise planning in the region. First, practices of coastal management have historically centered largely on construction of so-called grey infrastructure, including manmade levees and sea walls for flood protection. In contrast, the second imaginary, green infrastructure, prioritizes stewardship of coastal ecosystems such as wetlands to mitigate flood impacts. The third, environmental justice, foregrounds the social and political contexts in which debates over questions of coastal risk and protection take place. Based on 18 months of qualitative research, this paper argues that these competing imaginaries are intimately connected to the information infrastructures they use to understand sea-level rise as a problem and evaluate various solutions. Second, existing information infrastructure in the Bay exhibits an infrastructural bias. That is, it privileges some imaginaries at the expense of others. Finally, community-based organizations have a complex relationship with the data and information produced by engineers and other technical experts, seeking both to appropriate it to their own ends, and to resist the de-politicization that frequently accompanies expert framing of contentious issues.

\section{Related Work}

Climate change, disasters, and other environmental issues, like sea-level rise, are political, and these politics are intertwined with the technologies used to understand, prepare for, and respond to them [22][[47]. Decisions about what data to collect, the methods and standards used to collect it, and the algorithms, models, and techniques used to render it each meaningful inescapably encodes particular values and worldviews. In an oft-repeated phrase that 
captures this idea, "there is no such thing as raw data" [11][23]. This paper draws together research from human-computer interaction (HCI) and science and technology studies (STS) to consider the relationship between the politics of societal responses to environmental challenges and the technologies that are increasingly important to how we come to understand them. The protracted, slow-onset nature of sea-level rise provides an opportunity to examine this in detail, and especially yields insight into how different kinds of imaginaries and the information infrastructures that support them can emerge around ostensibly the same "issue".

\subsection{Infrastructuring Politics}

Scholars in HCI and STS have worked for several decades to articulate the relationships between information infrastructures, knowledge practices, technical work, and, to a lesser degree, politics. This line of research, crucially, collapses the fixed distinctions between social and technical components of such infrastructures, highlighting instead the various ways in which human capacities, social networks, organizations and institutions are as constitutive of infrastructure as the networks of cables and wires we might traditionally associate with the term. Other key insights from this work are the relational and processual nature of information infrastructure. Infrastructures may appear very differently to its different users, and, in important ways, are continuously in a state of becoming through interactions between their human and technical elements. The concept of infrastructuring thus describes how users of information infrastructure, such as the sea-level rise modelers and community activists in this study, appropriate available resources to their own ends in sometimes unexpected or surprising ways [27][44][46].

HCI research in civic technology has explored the relationship between knowledge politics and the work of infrastructuring public life. This work has largely drawn on philosopher John Dewey's notion of publics [15]. For Dewey, publics emerge in the event of externalities, or issues for which the current political system is not well equipped to address. Such externalities are overflows[18][50], which for various reasons go beyond the capacity of everyday governance institutions to manage and therefore emerge as problems, controversies, or contradictions that demand closer attention and broader participation from interested groups. Publics are thus groups of citizens with shared concern, or attachments, for these issues and, in Dewey's optimistic liberalism, are able to come together in a deliberative fashion to develop solutions. Civic technology has thus taken up questions of how technology design intersects with public formation and activity [31]. In this context, information infrastructures have a central role in constructing sea-level rise as a problem around which various publics can form, and as a result are vital components of the politics of sea-level rise planning in the Bay Area.

Here we seek to emphasize that the ways in which issues are articulated by information infrastructures shapes the sorts of associations that may arise, and the opportunities that are available to mobilize political action around them [38][48]. The intense uncertainties involved in sea-level rise create many surfaces upon which different sorts of attachments might be formed, and different kinds of publics may emerge. In addition, HCI research in participatory design and civic technology has considered the fraught and sometimes contentious relationship between communities and well-meaning technical experts from the outside. Relevant here is a recent argument by Le Dantec et al that "we need to interrogate how data-driven public processes may overshadow alternate narratives of how we engage in democratic society and collective action" [33]. As we will show, different visions of the relationship between environmental data and policymaking is central to debates over sea-level rise planning between community activists and civil engineering or coastal management experts in the Bay Area.

\subsection{Imagining Water}

Humanity's relationship to water is complex: water comprises a significant percentage of our bodies; we need to drink clean water frequently and regularly in order to survive; it is a necessary component of agricultural systems, and a key input to many industrial processes [20]. Water's role in supporting sanitation is also a core element in the promotion of public health in the modern era [20]. This complexity unsettles fixed understandings of the relationships and boundaries between nature, society and technology that are associated with Modernity [25][30]. Though we cannot exist without it, too much water in the wrong places is called "flooding", and societies everywhere take measures to protect lives and property in flood events [18]. Coastal communities have created defenses from simple barricades and walls, to complex locks, levies, and pumping systems for thousands of years. These infrastructures were shaped by, and in turn co-produced, local mechanisms of governance and politics [20]. For most of modern pre-industrial human history, these approaches were aided by the fact that sea levels have remained relatively constant [24], creating the illusion that coastlines were stable, even permanent, geographic features. Globally, sea levels began rising in the last century due largely to the effects of anthropogenic climate change. This shift will raise new challenges, and necessitate new kinds of politics.

The politics of sea-level rise will be shaped by the "imaginaries" that animate our understanding of it as a problem, in turn delimiting the kinds of solutions that may be considered. Imaginaries matter because they help to structure politics; they create some possible futures while foreclosing others. Jasanoff and Kim define socio-technical imaginaries as "collectively held, institutionally stabilized, and publicly performed visions of desirable futures, animated by shared understandings of forms of social life and social order attainable through, and supportive of advances in science and technology" [28]. Imaginaries are always uneven, partial, and contested. They each have issues on which they go into great details and other concerns on which they are silent. Further, they are dynamic, changing over time in response to socio-material conditions or other, competing, imaginaries. Far from being intangible, or existing solely in the heads of individuals, imaginaries, as Jasanoff and Kim discuss, are situated 
and collectively enacted, reinforced by custom, law, and as we discuss here, the information infrastructures that we use to understand the world and our place within it.

\section{Sea-level Rise in the Bay Area}

\subsection{Site Description}

Sea-level rise will be one of the most significant environmental challenges of the $21^{\text {st }}$ century. Hundreds of millions of people around the world live within a few feet of the coast [24], and are thus vulnerable to rising seas. In the Bay Area, as in so many other places, sea-level rise will intersect with numerous other factors shaping the region. Earthquake, wildfire, and flooding are also major concerns. As rising waters are shrinking the amount of land in the San Francisco Bay Area available to human activity, the region is facing the nation's most severe housing crisis, driven by the tech boom, land speculation, population rise and other factors. The region plays host to some of the most ethnically diverse cities in the nation, has served as a critical industrial and shipping hub for the US West Coast since World War II, been home to radical political organizations such as the Black Panther Party and the Free Speech Movement, and germinated an explosive nexus of technological expertise and finance capital in Silicon Valley. Debates over shoreline conservation and development are thus interwoven with a host of other concerns and bound up in the region's complex history.

The Bay Area, perhaps more than many parts of the United States, has significant technical expertise to respond to climate change, in addition to a public and political culture that acknowledges the role of climate change in driving the risks associated with sea-level rise. The region is home to multiple world-class universities, architecture and design firms, and non-profit organizations that seek to address the topic. This expertise is being cultivated and called upon by several high profile public initiatives aimed at achieving "resilience" to natural hazards and the impacts of climate change in the region. For example, the Rockefeller Foundation provided funding for several Bay Area cities to develop citywide resilience strategies. In 2017 and 2018, the region launched a competition, called Resilient by Design, which assembled teams of architects, urban planners, and engineers to develop infrastructural approaches to coping with sea-level rise. These regional efforts exist alongside multiple local projects in the over 60 cities, counties, and other jurisdictions along the Bay to model the potential impacts of sea-level rise and design responses.

To model the impacts of sea-level rise, practitioners use statistical and cartographic software to represent hydrological flows, the physical landscape of the Bay and low-lying coastal areas, and information about the communities exposed to rising waters. By bringing together diverse datasets including landcover, geology, physical infrastructure, economic activity, human population, wave, tidal and global climate projections, modelers attempt to estimate the consequences of sea-level rise under various climate futures and weigh the impacts of various approaches to coastal protection. Their work is dependent upon complex information infrastructures to which they themselves contribute but also includes physical sensors mounted on satellites or tide gauges, internet sites that catalog and make relevant data available, information standards that guide how data is collected and distributed, and professional associations and communities of practice that develop and share new methods and circulate best practices. The characteristics of these infrastructures shape our understanding of the impacts of sea-level rise, with important consequences for what parts of the San Francisco Bay shoreline will be protected and in what fashion.

Despite the many institutional advantages the region possesses, efforts to prepare for sea-level rise are beset by significant uncertainties. First, when considered on the long time scales of this slow-onset crisis, uncertainties stemming from various greenhouse gas emissions scenarios, rates of polar ice melt, and variations in local landscape [48] all make it very difficult to predict how much water to expect and where it will go. A recently released report on land subsidence showed that many parts of the region will have to prepare for rising waters while also taking into account gradual sinking of the region's shoreline developments built on soils characterized by soft bay mud [45], a factor not accounted for in most projections. Second, there are considerable interaction effects at play in efforts to mitigate sea-level rise. For example, if one municipality chooses to build a hardened shoreline barrier, flood effects may be exacerbated in adjacent areas. The lack of a central authority amongst the over one hundred city, county, and regional government entities in the Bay Area will complicate attempts to evaluate such interactions or respond to them in a coordinated manner [37]. These uncertainties create significant space for alternative and competing imaginaries of the issue to emerge.

\subsection{Research Methods}

This paper is based on 18 months of qualitative research in the Bay Area and had two phases. The first 12-month phase consisted of observation of numerous public and invitation-only meetings, events, and workshops where sea-level rise and climate change adaptation were being discussed. These included presentations by experts, community meetings in at-risk areas, and workshops that brought experts together around various relevant topics. In total, we estimate that we conducted about 60 hours of observation during this period. Our field notes from these events related primarily to how different actors relied upon information products such as maps, impact forecasts, and other data in the discussions. During this period we also focused on the differences between expert discourse on sea-level rise and the ways in which community activists and environmental justice groups framed the problem. Our observations were complemented by numerous informal conversations and review of technical reports, scientific studies, and software packages related to predicting the impacts of sea-level rise in the region and weighing various policy and planning responses.

In the second phase of the research, the authors conducted 19 semi-structured interviews with individuals working on different 
aspects of sea-level rise information or planning. Interview participants were identified based on personal and professional networks developed during the first phase of the study and selected to represent a diversity of perspectives, areas of expertise, and organizational affiliations. We developed two different interview schedules based upon the results of the first research phase. The first was for use with technical experts - scientists, engineers, spatial data analysts - and focused on the details of their work practices. With this group, we sought to understand how they produced their models, what information sources they relied on, and the challenges they encountered. We used the second interview schedule during interviews with staff of community-based organizations. These interviews focused on how these organizations engaged with data and information about sealevel rise, how they deployed it in their planning and advocacy efforts, and their views of its contributions and limitations. All interviews were recorded and transcribed.

To analyze interview and field-note data, the first and second author collaborated on developing an axial coding schema based on our observations and research questions. This schema was designed to assess how each of the three imaginaries at work in our field site constructed the problem of sea-level rise differently, how they related to one another, and the role of information infrastructures in these construction. After collaboratively coding our data, we produced a series of thematic memos that would become the major elements of the arguments presented in the following sections of this paper. While these findings are drawn directly from our observations of the San Francisco Bay Area, we expect that they will be relevant to sea-level rise and disaster planning in other areas as well as to HCI research on the relationship between data, communities, and the environment more broadly.

\section{Competing Imaginaries}

Our research into the various approaches to understanding sealevel rise in the Bay Area identified, broadly speaking, three distinct imaginaries. These perspectives aren't internally homogenous nor entirely exclusive. They exist both in tension and dialogue with one another. So while we are careful to avoid attributing a wholeness or coherence to these perspectives that they do not possess, there are enough regularities [40] across them to provide evidence of a strong discourse, or imaginary, that publics mobilize around in their efforts to shape the future of the region. To begin, we discuss two historically disparate technical disciplines, civil engineering and coastal resource management, that the issue of sea-level rise is has brought into conversation in region. We then explore how advocates of a third imaginary, environmental justice, contest the terms of this discussion by reassertion of the essentially political character of sea-level rise planning. For each of the three imaginaries we describe its scope and major features, and show the ways in which they, despite in some cases having roots that go back centuries, are today intimately intertwined with and dependent upon the characteristics of the information infrastructures used to understand and plan for sea-level rise.

\subsection{Grey Infrastructure: Command and Control}

Coastal engineering approaches evolved prominently in the Mediterranean Sea during the Bronze Age for the protection of harbors and ports to facilitate maritime trade [26]. Practices reliant upon hard structures like sea walls, jetties and breakwaters (often constructed by deploying large stones in linear arrangements) emerged as regionally-specific applications for rocky coastlines and deep water. While initially conceived as tactics for protecting discrete and spatially-constrained trade operations, these approaches have been deployed extensively to protect developed global shorelines, in particular made famous by the efforts of Dutch engineers to protect the low lying Netherlands from coastal inundation. In the modern era, concrete structures have often replaced stone as the common building material. Strategies reliant upon these structures are thus often characterized as "grey" infrastructure. Because of their durability, relative ease of construction and use of inexpensive materials; and the large body of knowledge about their design and performance under various circumstances as a function of their widespread use over long time periods, grey approaches for coastal engineering are widely evident in developed shorelines.

At present, less than $20 \%$ of the original coastline of the San Francisco Bay remains either undisturbed wetland or otherwise in a natural condition such as beach or bluffs [16]. Grey infrastructure projects are an important element of coastal management in the region, the most prominent example of which is undoubtedly the San Francisco seawall. Constructed between 1890 and 1917, the seawall establishes San Francisco's iconic bayshore, stretches for four miles and serves to stabilize the artificial fill and poor soils underlying the city and protect against coastal flooding. Behind it are ten's of billions of dollars in property, the SF downtown and financial district, and some of the most expensive commercial and residential real estate in the Western Hemisphere. Due to sea-level rise, the wall is regularly overtopped during high-tides, leading to minor, flooding in the area. The Port of San Francisco is currently planning to retrofit and update the now 100-year old sea wall. The retrofit is intended both to improve the seismic stability of the wall as well as increase its height to protect against sea-level rise, making it one of the most prominent coastal defense projects in the US.

From an information infrastructure perspective, one of the most important questions that engineers working on the seawall retrofit are trying to define is what level of protection - the height of the seawall - that the city should invest in. To do this, they rely primarily on cost-benefit analysis (CBA). CBA has been a central component of national flood management strategy in the United States since the Flood Control Act of 1936, which gave the federal government significant responsibility to invest in flood control measures, provided that the economic benefits of such measures exceeded the costs of their construction [41]. 100's of miles of levees, walls, and other defenses have been built under its auspices [41]. Central to the application of CBA in the case of the sea-wall are the data used for estimating the value of assets that will be protected - the benefit side of the equation. As is common for CBA 
approaches, "value" is considered in economic terms, and in the case of the sea wall, studies we examined considered only the real estate value of the land being protected, relying on publicly available government data.

The sea-wall modeling project is characteristic of other grey infrastructure studies conducted in the region. The spatial scale typically considered is that of the proposed intervention, and interaction effects with other parts of the Bay are often ignored. These models also take a long view of coastal management, typically using 50 or 100-year periods as the relevant planning horizon, estimating both the rate of SLR and the benefits of protection over that time period. Despite the complex phenomena under consideration, these models, at root, are seeking to answer a relatively straightforward set of questions around the likely impact of various sea-level rise scenarios and the efficacy of various protective measures. The structure of the models, and the form of their results have been shaped by decades of interaction with the legal and bureaucratic structures governing coastal management. To accomplish their work, the practitioners who develop these models are able to draw upon a wide range of resources, including existing data, well-established and documented methodologies, and an extensive community of practice spanning the civil engineering and planning disciplines.

As an imaginary, grey infrastructure approaches are often rooted in what has been described as a "command and control" ethos [39]. Water is treated as a threat: something to be kept at bay or disciplined through channels or pumping systems. For a variety of reasons, this orientation is being reexamined by planners and policy-makers. Extensive literature has documented the ecological shortfalls of these approaches, which often accelerate erosion and other detrimental geophysical processes; disrupt or degrade habitat for native species and negatively impact biodiversity in general. Grey approaches, through their tendency to increase erosion and shunt floodwaters, may "telegraph" flooding to adjacent reaches of a given shoreline, raising important ethical and equity questions. And because grey approaches are generally static in nature, they may behave as brittle components on a coastal engineering scheme, occasionally failing catastrophically. As such, they are costly to repair or replace, and, because of their static nature, are often cumbersome, expensive and limited in terms of adapting their design for changing environmental conditions or performance required by the uncertain future sea level conditions.

\subsection{Green Infrastructure: Living With Water}

As an alternative to grey infrastructure, modern coastal planners are increasingly beginning to experiment with a set of practices known collectively as green infrastructure. Planning and resource management practitioners have relied upon natural processes to promote environmental sustainability and quality of life in coastal cities for centuries. Prominent examples of embracing natural features (like topography or hydrology) ecosystem services (such as air and water quality improvements), and approaches that stressed development schemes intended to "build with nature" are evident in many coastal metropolitan areas. In the SF Bay Area, the green approach to shoreline protection has manifested in connection with decades-long, large-scale ecological restoration efforts of thousands of acres of tidal marsh plains that were filled as part of development schemes over the past century and half. As a result, green approaches are emerging as a novel challenge to the dominant grey imaginary, which is often framed by critics as being both imported and out of date. In the words of one practitioner, "We're not the Netherlands, and this isn't the $19^{\text {th }}$ century".

The South Bay Salt Ponds (SBSP) in the southern SF Bay is the focus of the largest tidal wetland restoration project on the West Coast of the United States and a representative example of the green imaginary as it is enacted in the Bay Area. The project was launched in the late 1990's, when thousands of acres of previously diked and disconnected salt evaporation ponds run by Cargill corporation were acquired by state government Today, they are being reconnected to the tidal rhythms of the Bay as part of efforts to restore ecological functionality and create a large flood protection infrastructure for adjacent communities. The SBSPs is an ambitious example of the green imaginary's approach, as it relies on ecological processes to deliver multiple benefits including shoreline protection also providing open space for public recreation and. The project is designed and implemented according to principles of adaptive management, whereby planning cycles are short - often in the range of three to five years - and new data about local conditions is continuously gathered in order to judge the results of prior interventions and experiment with alternative approaches as needed.

Though in principle the data, models, and performance standards used for designing and evaluating green infrastructure projects are meant to answer similar questions as the grey models - the location, frequency, and impacts of coastal flooding due to sealevel rise, in practice they are quite distinct. SBSP serves as a largescale, continuously evolving experiment that generates data for analysis and adaptive management and planning: the iterative process of evaluation and decision-making that governs that project. As discussed above, this means more frequent data collection and shorter future horizons are considered by green models. In addition, practitioners of the green imaginary, in an attempt to fit into the planning discourse established by the grey imaginary, have adopted the logics of cost-benefit analysis. Yet, unlike they grey imaginary that understands "benefit" to mean the economic value of protected real estate, green approaches pursue multi-benefit valuation strategies that include protection of other goods including recreational use by neighboring communities or the provision of habitat for endangered species. This means that engaging a much wider suite of domain expertise, data inputs and modeling techniques is required for understanding how rising seas will interact with planning processes drawing upon the green imaginary.

If the grey imaginary can be described as a command and control orientation to coastal management, then the green imaginary is about "living with water" [20]. Instead of treating water as a threat 
to be excluded from human settlements, advocates understand it as a resource, and design systems that include and accommodate its processes in spatial terms. This allowance seems to respond to many of the weaknesses of the command and control imaginary, but raises its own challenges. Apart from the different modeling and information requirements of these techniques, 'green' shoreline schemes often hinge upon the utilization of large areas to accomplish flood mitigation goals, since wetlands act as floodplain buffers - gradually sapping energy from storm-driven waters. In practice, this may mean that some coastal neighborhoods would not be protected under green approaches. Additionally, adaptive management implicitly entails flexible phasing/master-planning efforts, and regularly responds to updating projections and data regarding sea-level rise and the SBSP performance over time, and taking into account as-yet unknown economic and political changes in the region that could lead to alternate planning priorities.

\subsection{Environmental Justice}

In addition to the futures envisioned by proponents of grey and green imaginaries, a heterogeneous collection of activists, community organizers, and non-profit organizations in the Bay Area have been working to articulate the threat posed by sea-level rise from the perspective of environmental justice. In the United States, the environmental justice movement arose in the early 1980 s in response to activist concerns over unequal impacts of pollution on minority communities [13]. In the Bay Area, environmental justice advocacy has historically focused on the disproportionate burden faced by predominantly minority neighborhoods of air pollution, soil contamination, and unsafe drinking water [14]. Only in recent years have questions of "climate justice", including sea-level rise, been taken up as a serious concern. However in many parts of the region, it is these same neighborhoods where environmental justice advocates have focused that are most exposed to sea-level rise impacts. Many neighborhoods in the Bay Area, were destinations for Africa Americans during the "Great Migration" out of Southern States in the mid- $20^{\text {th }}$ century [29]. For example, due to proximity to job opportunities and discriminatory housing policies, many new arrivals attracted by the shipping boom at the Port of Oakland during and after World War II moved to the very low-lying areas that are now vulnerable to sea-level rise [4].

Environmental justice advocates interacted with information infrastructures related to sea-level rise quite differently than the other imaginaries we studied. Public presentations given by staff or volunteers from environmental justice organizations often didn't include any of the usual statistics of forecasted impacts, maps of inundated areas, or graphs projecting the rate of sea-level rise that dominated presentations of the issue developed by either the grey or the green approaches. In addition, their public materials often included topics such as gentrification and deplacement, community relations with law enforcement, or funding for public schools that were, on the surface, unrelated to sea-level rise. Yet, as some HCI research has argued, the inclusion of the wide range concerns faced by disadvantaged communities is in fact central to approaches that center justice as a core value [17]. As one advocate we interviewed explained, "We talk about adaptation and resilience from a very holistic perspective. We are being hit with so many things right now." This broadened and more contextualized perspective on the impact of sea-level rise led community groups to engage with information about the topic in different ways than participants in either the grey or green imaginaries.

A key fault-line in the debate between environmental justice advocates and proponents of other imaginaries is the role of technical expertise in public decision-making. Indeed, almost all the groups we interviewed raised the difficulty of challenging the recommendations of scientists and engineers, and described feeling disempowered by public discussion oriented around the complex, technical models deployed by civil engineers or coastal resource managers. They related, in many cases, being unable to participate on an equal footing with technical experts (see also [7]). However, at the same time, where strategic, they used the data produced by experts as a means to inform and mobilize their communities. HCI research in participatory design and civic technology has sought to transcend this difference, arguing that partnerships between technical experts and community organizers can be productive and mutually beneficial if significant investments in relationship building and developing shared understanding are made [32]. In the Bay Area, we found that while several attempts at this work are underway, a significant divide remains between environmental justice organizations and sealevel rise experts. These dynamics are described further in Section 5.2 of the paper, below.

Imaginaries, as with all discourses about the future, always take flight from a particular location. They are situated in a particular context and relationship to the present. One way to understand the logics and political valence of various imaginaries, then, is to examine what they hold constant, as compared to what they envision is malleable or open to change in the future. The grey and green imaginaries, guided by scientific and technical expertise, reinforce contemporary social and political arrangements by essentially leaving them unchanged while envisioning different ways of living with water in the region. By comparison, environmental justice advocates challenge the status quo on a much wider range of issues. By not addressing questions of gentrification or unequal distribution of the harmful effects of climate change in their imaginaries, both grey and green approaches in effect serve to naturalize these issues, treating them as either unproblematic or immutable. By raising questions of inequality and racism into policy debates dominated by a more narrow technical discourse, environmental justice organizations are raising the possibility of an alternative imaginary, prioritizing values of justice and equity over narrowly focused technical expertise.

\section{Discussion}

Imaginaries aren't static. Nor are they complete, as they are continually being enacted and re-articulated by their proponents. 
In the course of ongoing debates over politics and policy, they can interact in surprising and unexpected ways. Indeed, most of the technical experts that we encountered accepted that some mix of "green" and "grey" infrastructure was desirable for coastline protection, and conceded that the perspective of environmental justice drew important attention to important blind spots or silences in the models and maps they put forward. To help articulate some of the ways in which these imaginaries compete and interact and the role of information infrastructures in these processes, we offer two arguments in the closing section of this paper. The first is that the information infrastructure that enables understanding of sea-level rise, as currently constituted in the Bay Area has a bias toward the grey imaginary, supporting a command-and-control relationship with the coastline. Second, we identify four tactics used by environmental justice advocates use to resist the technical framing of the green and grey imaginaries and reassert the fundamentally political character of sea-level rise information.

\subsection{Infrastructural Bias}

The networks of human, social, and technological resources that are used by experts, policy-makers, and the public to understand and plan for sea-level rise currently provide greater support to the development of models and analyses that align with the grey imaginary. This allows proponents of this imaginary to more easily and effectively present their vision for coping with the challenge of sea-level rise. These advantages are not surprising. The suite of tools and approaches that comprise the grey infrastructure approach to coastal protection have a long history in research and practice and are closely linked to the bureaucratic and legal mechanisms that have developed around the governance of coastal protection. In contrast, many of the practitioners and experts we interviewed characterized the green approach as being "in the information wilderness" as one practitioner illustratively described, or least emergent and untested. Here we consider the role of information infrastructures in sustaining this situation.

From a technical perspective, the information infrastructure that the grey imaginary utilizes is robust and well-developed. The civil engineers we interviewed that work in this area were able to rely for the most part on existing data and software to carry out their analysis, allowing them to work faster, at less expense, and with greater confidence in their results. Conversely, practitioners working within the green imaginary are frequently forced to collect their own data or devise new means of gathering information. One example of this challenge relates to temporality of the data required to inform sea-level rise models. Models produced in the context of the grey imaginary require data about the condition of the coast and the property value exposed to coastal flooding once, at the start of the project, in order to determine the level of protection to design for timespans of 50 to 100 years. The adaptive management techniques deployed as part of the green imaginary, on the other hand, requires the periodic monitoring of results. New data is collected frequently in order to evaluate the results of previous interventions and iterate accordingly. In discussing this difficulty, one of our interviewees told us that they were investigating the use of drones, partnerships with community groups to conduct citizen science monitoring of the coast, and automated classification of satellite imagery in order to try to keep up with the rapidly changing coastline. They said,

It takes a lot of work to produce and maintain these maps and datasets. We need to find new ways to keep up, to incorporate these interventions, new green infrastructures. Right not we don't have a way account for all this stuff.

Further, the green imaginary's expansive definition of "value" means that, unlike grey models which typically rely data on property values from public records or other existing sources, green imaginaries seek to account for non-market values like habitat for endangered species or public use and recreation. The challenges of bringing such values into commensurability with the exchange value of commodity, like property, is well documented within the environmental economics literatures [12] and was highlighted by many of our interviewees. One team working on the design of a green infrastructure project in the southern part of the Bay was forced to develop and maintain a new database on fish population in order to understand the impact of their work in the area on biodiversity and track change over time. Another relied on complex calculations in an attempt to assign monetary figures to the value of public parks to residents for recreation purposes.

In addition to its technical components, most formulations of information infrastructure now also take into account the social elements of its construction [34][43][46]. This includes individuals and their relationships as well as communities of practice, technical standards, and legal and economic institutions of various types. In the Bay Area we found that these aspects also exhibit bias in favor of the grey imaginary. For example, the lack of social and professional consensus surrounding the modeling approaches being developed by coastal restoration experts within the wider community that engages with coast planning translates into lack of professional support for practitioners and heightened uncertainty about how to interpret or evaluate the results of their models. One coastal ecologist told us, that in compared to proponents of the grey imaginary:

\section{We're weaker on turning data and models into decisions. There's not an agreed upon methodology for incorporating social values, historic preservation, and the other kinds of things that don't fit neatly into the models used by engineers and planners.}

The resulting uncertainty around the information and modeling practices deployed in green imaginary projects is also reflected in the risk tolerances and performance standards developed by engineers and encoded into policy and regulation. The ecologist quoted above went onto complain that the standards of evidence required for permitting protective interventions were outmoded, privileging the construction of permanent barriers, grey 
infrastructure, over more permeable or adaptive solutions. They said, "we're bound by regulations developed in the 1970's. Our institutions aren't very nimble.” Another project manager related the difficulty of partnering with a federal agency whose regulations mandated an altogether different set of data and models on coastal protections than that which would be used to design and evaluate adaptive management processes.

In the SF Bay, advocates of the green imaginary struggle to access and utilize the resources offered by information infrastructure in ways that their colleagues working on grey approaches often take for granted. This negatively impacts their ability to advocate for responses to sea-level rise that align with their values and beliefs. Research on the role of data in public life has raised questions of algorithmic bias, focusing on how these technologies can reproduce structural inequalities along lines of class, race, gender, and sexuality in settings as diverse as law enforcement and hiring practices [11][23]. Here we find the roots of such biases running both deeper and wider, into the socio-technical information infrastructure underpinning algorithms, and extending to the imaginaries that shape our politics and visions of the world around us.

\subsection{Rendering Technical and Resistance}

A common feature of both the grey and green imaginaries is that they are both shaped, to a large extent, by scientific and technical expertise. As discussed, the design of grey infrastructures is informed by a long tradition of research and practice in civil engineering. Green infrastructure inevitably relies upon a range of disciplines, but draws from ecology and coastal restoration practice in particular. Tanya $\mathrm{Li}$, in her anthropology of the relations between governance and expert technical knowledge, argues, "questions that are rendered technical are simultaneously rendered nonpolitical"[35]. Technical expertise here relies on a sort of discursive closure [48] that brackets away contentious social or political questions in order to reduce the matter at hand to something amenable to expert, presumptively "neutral" intervention. However, this practice of rendering technical, to use Li's phrasing, is never neutral, complete, or uncontested. Community groups, resisting the framing of both green and grey imaginaries and instead advocating for imaginaries rooted in justice, deploy a range of tactics to resist the closures produced by expert knowledge and reassert the political character of sea-level rise planning.

The first tactic used by environmental justice organizations to resist the de-politicization of the question of sea-level rise is differentiating its effects on different communities. With some notable exceptions ${ }^{1}$, maps, models, and projections of sea-level rise in the Bay Area typically don't account for the ways low-resource communities are often both more exposed to coastal flooding and less able to cope with its impacts. The statistical aggregates that

\footnotetext{
${ }^{1}$ The Bay Area Adapting to Rising Tides (ART) project, includes metrics of social vulnerability to sea-level rise, see: http://www.adaptingtorisingtides.org/maps-anddata-products/
}

are generally used to discuss the potential impacts of sea-level rise effectively work to mask significant variability in who will be affected by coastal flooding, and their ability to mitigate its impacts and recover in the aftermath. One community organizer told us that, "one of the biggest problems of disadvantaged communities is that they are segregated and there's like an information shield so people don't know what's happening there... or they don't want to know". As a public, the environmental justice movement emerged in order to highlight and address these disparities. By continually raising awareness about them in public discussion of sea-level rise, activists call into the question the supposedly neutral character of the models produced by experts.

The second is by complicating the matter. In contrast to the reductive character of expert discourses of sea-level rise, environmental justice groups continuously raised issues such as gentrification, racism, or police violence against communities of color to paint a richer picture of the challenges faced by their constituents. This served to re-situate the threat of sea-level rise within the complex and dynamic milieus in which it is occurring. One advocate complained that the dominant discussion about SLR in the Bay Area was only leading to superficial solutions, in part because they were not involving at-risk communities. They said, "as an environmental justice organization we have to be grounded in what our communities are prioritized and what they are facing." This organization did use data and models selectively, as useful, to mobilize and inform their constituents, but they decentered it, and put the drivers and impacts of the problem in a wider context. By introducing a range of questions that fall outside of the domain of technical experts to the discussion, environmental justice groups seek to resist the technical prescriptions offered by experts and mobilize alternate sorts of publics around the issue.

In a related fashion, activists worked at localizing the discussion over sea-level rise, and in turn establishing their own valid form of knowledge based on their relationship to place - the communities where they live and work. These groups, as a result of their connection to a particular neighborhood or community, were able to claim knowledge of these places that technical experts did not possess. They used what participation research has termed local knowledge [1] to contest the accounts of experts, who were often painted as transient outsiders. In one case, residents used their past experience of flooding in their community to argue, successfully, that the authoritative, regional-scale, model of sealevel rise mischaracterized which areas of their community would be vulnerable to sea-level rise. The model was eventually altered as a result. In another example, during a public meeting about sealevel rise a well-known environmental justice advocate stated that if experts wanted to partner with community organizations on the issue that "they had better come correct," meaning that they needed to acknowledge and respect the priorities and knowledge of the local community over pushing their own outside agenda.

Finally, narrative was an important tactic used by the environmental justice groups we interviewed. In discussing their vision for the future, advocates would often stress the rich history 
of activism in the Bay Area, and seek to contribute to communities' sense of pride by telling stories about, in the words of one, "thriving in the face of adversity." One advocate argued that a plausible "story" of how a community would manage to successfully adapt to climate change and the other factors influencing the future of the region as being of equal if not greater importance to the necessary scientific modeling, data, or even project funding. HCI research has examined the role of environmental data in creating and shaping narratives [5]. In our research we found that activists and community organizations draw upon their own narratives in order to place their agenda in conversation with, and sometimes in opposition to, the data used in support of the imaginaries articulated by technical experts.

Conflicts over data between experts and community activists are not uncommon. In some cases, environmental justice groups have used low-cost sensors to collect their own data to challenge official statistics e.g. [3]. These sorts of projects, often called participatory mapping or citizen science, seek to translate local knowledge into authoritative data through adherence to recognizable data collection methodologies [51]. In this case however, activists sought to reframe the discussion of what kind of information mattered to discussion of sea-level rise in the first place and how it should be evaluated. Here we see them using the tactics we identified to reassert control over the imaginary of their communities by influencing about how sea-level rise data "comes to matter" [49]. These findings are important to HCI research and practice in civic technology and public design in two ways. First, they provide researchers and designers dynamics that they might encounter, and thus need to be aware of, in their own field sites. Second, designers and participatory researchers could design tools and processes that would augment and support the tactics deployed by justice organizations to articulate their imaginaries.

\section{Conclusion}

As part of a discussion on prospects for sea-level rise planning in the region, an engineer told us, "from a technical standpoint, we have this issue solved. The problem is politics." Over the course of our careers, we've heard similar sentiments from experts working across a wide range of technical domains and geographies. In some ways, these arguments are representative of a classic "inside/outside" problem in philosophy of science and STS. In our field-site we witnessed experts working inside their discipline to update their models and forecasts and community organizations working on the outside to reassess how model results and projections should be situated within wider political debates. At the same time, the concept of the imaginary helps us to see the ways in which this technical/political binary isn't quite as solid as the engineer we spoke with would seem to suggest. Imaginaries, as we have shown here, draw our attention to the ways in which the technical and political co-produce one another. This paper is, in part, about how that works, and the role of information infrastructures in shaping these dynamics.

We have argued that, first, important HCI concerns with the role of data and software in public life should also be addressed to research on information infrastructure. Infrastructural bias, as we have termed it, is an issue that runs both broader and deeper than much of the work in this area currently accounts for. The concept of the socio-technical imaginary, drawn from science and technology studies, helps to illustrate this connection and assess the relationship between technology and politics. In the Bay Area, the privileging of the grey, or command and control, response to rising sea-levels is founded in the ways in which sea-level rise is articulated by the technical and social components of the information infrastructure used to understand the problem. In addition, we have articulated some of the tactics used by community organizations to reassert the fundamentally political character of sea-level rise and advocate for their own approach to responding to the issue.

Taken together, these findings point toward what we might think of as a turn to discourse in infrastructure studies. Bowker has written that "(w)e all too rarely think about the ways in which our social, cultural and political values are braided into the wires, coded into the applications, and built into the databases which are so much a part of our daily lives"[8]. We agree that the development of a richer conceptual apparatus for describing the ways in which information infrastructures shape our sociotechnical imaginations, and vice versa, is necessary. As a species, humanity is still grappling with the implications of the incredible changes in understanding of the world around us that advances in technology over recent decades have granted us. This task, though extraordinarily complex, is underway in much of the literature in critical data studies, STS, and HCI that we have engaged with throughout this paper. We add our findings to this body of work and hope that other HCI scholars will be encouraged to take up these questions in their own research.

\section{ACKNOWLEDGMENTS}

This research was funded by US National Science Foundation Grant AGS-1331490. The authors wish to thank our interview participants and the numerous other individuals and organizations who helped us understand the complexities of sea-level rise data and politics in the Bay Area.

\section{REFERENCES}

[1] Abdelnour-Nocera, J., Clemmensen, T. and Kurosu, M., 2013. Reframing HCI through local and indigenous perspectives. International fournal of HumanComputer Interaction, 29(4), pp.201-204.

[2] Ames, M.G., 2015. Charismatic technology. In Proceedings of The Fifth Decennial Aarhus Conference on Critical Alternatives (pp. 109-120). Aarhus University Press.

[3] Aoki, P., Woodruff, A., Yellapragada, B. and Willett, W., 2017, May. Environmental Protection and Agency: Motivations, Capacity, and Goals in Participatory Sensing. In CHI (pp. 3138-3150).

[4] Bagwell, B., 1982. Oakland: The story of a city. Presidio Press.

[5] Baker, K.S., Bowker, G.C. and Karasti, H., 2002, May. Designing an infrastructure for heterogeneity in ecosystem data, collaborators and organizations. In Proceedings of the 2002 annual national conference on Digital government research (pp. 1-4). Digital Government Society of North America.

[6] Bay Conservation and Development Corporation (BCDC). 2011. Living with a rising bay: Vulnerability and adaptation in San Francisco Bay and on its shoreline. BCDC.

[7] Bopp, C., Harmon, E. and Voida, A., 2017, May. Disempowered by data: Nonprofits, social enterprises, and the consequences of data-driven work. In CHI Conference (pp. 3608-3619). 
[8] Bowker, G. 2014. The Infrastructural Imagination. In: Mongili, A. and Pellegrino, G. eds., 2014. Information infrastructure (s): Boundaries, ecologies, multiplicity Cambridge Scholars Publishing.

[9] Burrito Justice. 2012. Islands of Justice. Viewed September 7, 2018 <https://burritojustice.com/2012/03/20/san-francisco-archipelago>

[10] Chen, J., 2015. Computing within limits and ICTD. First Monday, 20(8).

[11] Crawford, K., Gray, M.L. and Miltner, K., 2014. Big Data| critiquing Big Data Politics, ethics, epistemology| special section introduction. International Journal of Communication, 8, p.10.

[12] Daily, G.C., Polasky, S., Goldstein, J., Kareiva, P.M., Mooney, H.A., Pejchar, L., Ricketts, T.H., Salzman, J. and Shallenberger, R., 2009. Ecosystem services in decision making: time to deliver. Frontiers in Ecology and the Environment, 7(1), pp.21-28.

[13] Dawson, A., 2010. Climate justice: the emerging movement against green capitalism. South Atlantic Quarterly, 109(2), pp.313-338.

[14] Dillon, L., 2018. The Breathers of Bayview Hill: Redevelopment and Environmental Justice in Southeast San Francisco. Hastings Environmental Law Journal, 24(2), p.227.

[15] DiSalvo, C., Lukens, J., Lodato, T., Jenkins, T. and Kim, T., 2014, April. Making public things: how HCI design can express matters of concern. In SIGCHI (pp. 2397-2406).

[16] Doehring, C., Beagle, J., Lowe, J., Grossinger, R., Salomon, M., Kauhanen, P. Nakata, S., Askevold, R. and Bezalel, S., 2016. San francisco bay shore inventory: mapping for sea level rise planning.

[17] Dombrowski, L., Harmon, E. and Fox, S., 2016, June. Social justice-oriented interaction design: Outlining key design strategies and commitments. In Proceedings of the 2016 ACM Conference on Designing Interactive Systems (pp. 656-671).

[18] Donaldson, A., Lane, S., Ward, N. and Whatmore, S., 2013. Overflowing with issues: following the political trajectories of flooding. Environment and Planning C: Government and Policy, 31(4), pp.603-618.

[19] Dutta, P., Aoki, P.M., Kumar, N., Mainwaring, A., Myers, C., Willett, W. and Woodruff, A., 2009, November. Common sense: participatory urban sensing using a network of handheld air quality monitors. In Proceedings of the 7th ACM conference on embedded networked sensor systems (pp. 349-350).

[20] Edwards, P.N., 2010. A vast machine: Computer models, climate data, and the politics of global warming. Mit Press.

[21] Gandy, M., 2014. The fabric of space: Water, modernity, and the urban imagination. MIT Press.

[22] Fortun, K., 2004. From Bhopal to the informating of environmentalism: risk communication in historical perspective. Osiris, 19, pp.283-296.

[23] Gitelman, L. ed., 2013. Raw data is an oxymoron. MIT Press.

[24] Griggs, G., 2017. Coasts in Crisis: A Global Challenge. Univ of California Press.

[25] Haraway, D.J., 1985. A manifesto for cyborgs: Science, technology, and socialist feminism in the 1980s (pp. 173-204). San Francisco, CA: Center for Social Research and Education.

[26] Hill, K., 2015. Coastal infrastructure: a typology for the next century of adaptation to sea-level rise. Frontiers in Ecology and the Environment, 13(9), pp.468-476.

[27] Jack, M., Chen, J. and Jackson, S.J., 2017, May. Infrastructure as Creative Action Online Buying, Selling, and Delivery in Phnom Penh. In Proceedings of the 2017 CHI Conference on Human Factors in Computing Systems (pp. 6511-6522). ACM.

[28] Jasanoff, S. and Kim, S.H. eds., 2015. Dreamscapes of modernity: Sociotechnical imaginaries and the fabrication of power. University of Chicago Press.
[29] Johnson, M.S., 1994. The Second Gold Rush: Oakland and the East Bay in World War II. Univ of California Press.

[30] Latour, B., 2012. We have never been modern. Harvard university press.

[31] Le Dantec, C.A.. and DiSalvo, C., 2013. Infrastructuring and the formation of publics in participatory design. Social Studies of Science, 43(2), pp.241-264.

[32] Le Dantec, C.A. and Fox, S., 2015. Strangers at the gate: Gaining access, building rapport, and co-constructing community-based research. In CSCW (pp. 13481358).

[33] Le Dantec, C.A., Asad, M., Misra, A. and Watkins, K.E., 2015. Planning with crowdsourced data: rhetoric and representation in transportation planning. In CSCW (pp. 1717-1727).

[34] Lee, C.P., Dourish, P. and Mark, G., 2006. The human infrastructure of cyberinfrastructure. In Proceedings of the 2006 20th anniversary conference on Computer supported cooperative work (pp. 483-492).

[35] Li, T.M., 2007. The will to improve: Governmentality, development, and the practice of politics. Duke University Press.

[36] Light, A., Shklovski, I. and Powell, A., 2017, May. Design for existential crisis. In $\mathrm{CHI}$ Conference Extended Abstracts on Human Factors in Computing Systems (pp. 722-734).

[37] Lubell, M., 2017. The Governance Gap: Climate Adaptation and Sea-Level Rise in the San Francisco Bay Area. University of California, Davis.

[38] Marres, N., 2007. The issues deserve more credit: Pragmatist contributions to the study of public involvement in controversy. Social studies of science, 37(5), pp.759-780.

[39] McPhee, J., 2011. The control of nature. Farrar, Straus and Giroux.

[40] Murphy, M., 2006. Sick building syndrome and the problem of uncertainty: Environmental politics, technoscience, and women workers. Duke.

[41] Pearce, D., 1998. Cost benefit analysis and environmental policy. Oxford review of economic policy, 14(4), pp.84-100.

[42] Peet, R. and Watts, M., 2004. Liberation ecologies: Environment, development and social movements. Routledge.

[43] Pine, K.H. and Liboiron, M., 2015.. The politics of measurement and action. In CHI (pp. 3147-3156).

[44] Pipek, V. and Wulf, V., 2009. Infrastructuring: Toward an integrated perspective on the design and use of information technology. Journal of the Association for Information Systems, 10(5), p.1.

[45] Shirzaei, M. and Bürgmann, R., 2018. Global climate change and local land subsidence exacerbate inundation risk to the San Francisco Bay Area. Science advances, 4(3), p.eaap9234.

[46] Soden, R. and Palen, L., 2016. Infrastructure in the wild: What mapping in postearthquake Nepal reveals about infrastructural emergence. In CHI (pp. 27962807).

[47] Soden, R. and Palen, L., 2018. Informating Crisis: Expanding Critical Perspectives in Crisis Informatics. In CSCW. 162...

[48] Soden, R., Sprain, L. and Palen, L., 2017, May. Thin Grey Lines: Confrontations With Risk on Colorado's Front Range. In CHI (pp. 2042-2053).

[49] Taylor, A.S., Lindley, S., Regan, T., Sweeney, D., Vlachokyriakos, V., Grainger, L. and Lingel, J., 2015, April. Data-in-place: Thinking through the relations between data and community. In Proceedings of the 33rd Annual ACM Conference on Human Factors in Computing Systems (pp. 2863-2872). ACM.

[50] Whatmore, S.J. and Landström, C., 2011. Flood apprentices: An exercise in making things public. Economy and society, 40(4), pp.582-610.

[51] Wilson, M.W., 2011. Data matter (s): legitimacy, coding, and qualifications-oflife. Environment and Planning D: Society and Space, 29(5), pp.857-872. 